\title{
TOXICITY PROFILE OF CELASTRUS PANICULATUS SEEDS: A PRECLINICAL STUDY
}

\author{
BHARAT MISHRA*, ELEZABETH JOHN, KRUPAMOL JOY, BADMANABAN R, ALEESHA R
}

Department of Pharmacology, Nirmala College of Pharmacy, Ernakulam, Kerala, India. Email: bharatekansh@gmail.com

\author{
Received: 28 March 2020, Revised and Accepted: 08 May 2020
}

\begin{abstract}
Objective: The objective of the study was to evaluate the toxicity profile of Celastrus paniculatus (CP) by performing a preclinical study on Swiss albino mice and demonstrate a safety description through monitoring their autonomic, neurological, behavioral, physical, and biochemistry profiles.

Methods: The toxicity profiles (acute and subacute) of CP were evaluated using Swiss albino mice in which they were divided into four groups: Group I received 1\% Tween 20 and dimethyl sulfoxide. Group II, III, and IV received CP seed oil orally, at doses of 300, 2000, and 5000 mg/kg body weight for both acute and subacute toxicity studies in accordance with Organization for Economic Cooperation and Development guidelines No. 423. Special attention was given during the first $4 \mathrm{~h}$ and daily thereafter for a total of 14 days. Behavioral profile, physical state changes, and other parameters such as tremors, convulsion, lethargy were noted. Clinical signs were observed daily during the 28 days of the treatment period. Body weights were measured once a week. On the $29^{\text {th }}$ day, the animals were kept to overnight and blood samples were collected through retro-orbital puncture for biochemical analysis.
\end{abstract}

Results: In both acute and subacute toxicity studies, the treatment with CP did not affect the normal health status of animals. It is suggestive that CP is considered practically non-toxic.

Conclusion: The toxicity profile of CP seed oil was evaluated and found to be safe until $2000 \mathrm{mg} / \mathrm{kg}$ dose.

Keywords: Celastrus paniculatus, Acute toxicity, Subacute toxicity, Treatment, Safety.

(c) 2020 The Authors. Published by Innovare Academic Sciences Pvt Ltd. This is an open access article under the CC BY license (http://creativecommons. org/licenses/by/4. 0/) DOI: http://dx.doi.org/10.22159/ajpcr.2020.v13i7.37803

\section{INTRODUCTION}

Herbal plants have been used from ancient times for the treatment of several diseases in the indigenous system of medicine [1]. Celastrus paniculatus (CP) Wild. (Family: Celastraceae) [2], commonly known as Malkangni (in Hindi) or Jyotishmati (in Sanskrit) and commonly known as black oil plant, climbing staff tree (in English) [3] is a long established medicinal plant which has been used extensively in the Ayurvedic system for its recognized analgesic, anti-inflammatory, and marked central effects such as memory boosting and antiepileptic effects [4]. The use of the plant parts in the treatment of several ailments can be attributed to the potential effects of its various phytoconstituents. The seeds of the plant when extracted with petroleum ether yield dark brown oil known as Celastrus oil or Malkangni oil are known to have an effect on the central nervous system, mainly the memory-enhancing activity and stimulating effects [3]

The neuropharmacological effects of this herb are striking and the seeds have been reported to possess antidepressant [5], anxiolytic [6], antioxidant [7], hypolipidemic, anti-atherosclerotic, anti-stress, antispermatogenic, nootropic activities, and relaxant effects on smooth muscles [8]. Celastrus oil therapy in mentally retarded children results in an improvement in their intelligence quotient as it contains a number of fatty acids such as oleic, linoleic, linolenic, palmitic, stearic, benzoic, and acetic acid as volatile acids and their glycerol esters mainly $\alpha$, $\alpha$ ' dipalmitoyl glycerol. They also contain sesquiterpene alkaloids celapanin, celapanigin celapagin, and malkangunine [9].

Toxicology is an important aspect of pharmacology that deals with the adverse effects of bioactive substances on living organisms before the use as drug or chemical in clinical use. Plants or drugs must be ensured to be safe before they are employed as medicines because the potential toxicity of herbal plants has been recorded [10]. A key stage in ensuring the safety of drugs is to conduct toxicity tests in appropriate animal models.
Although animal toxicity studies of the CP seeds have not yet been established before, it is widely used because of its many beneficial effects and this research is focused on establishing the safety profile of the plant so that they may be credibly employed for various therapeutic applications in medicine.

\section{METHODS}

Plant collection and extraction

CP (greenwood essential) seed oil was purchased from a registered, authentic source. The seed oil is administered orally as o/w emulsion, prepared by the wet gum method.

The vehicle employed was phosphate buffer saline, prepared using 4 $\mathrm{g}$ of sodium chloride, $100 \mathrm{mg}$ of potassium chloride, $0.72 \mathrm{~g}$ of sodium hydrogen phosphate, $120 \mathrm{mg}$ of potassium hydrogen phosphate, and $500 \mathrm{ml}$ distilled water. All the components were initially dissolved in $400 \mathrm{ml}$ distilled water, then the $\mathrm{pH}$ was adjusted to 7.4 and was diluted to $500 \mathrm{ml}$ with distilled water [11]

\section{Phytochemical screening}

Phytochemical screening for carbohydrate, protein, amino acid, alkaloid, tannins, steroid, terpenoid, volatile oil, glycoside, and fixed oil had been carried out.

\section{Preparation of $100 \mathrm{ml} \mathrm{CP} \mathrm{o/w} \mathrm{emulsion} \mathrm{by} \mathrm{wet} \mathrm{gum} \mathrm{method}$} The proportion of oil:water:gum for preparing primary emulsion is $4: 2: 1$. The required quantity of acacia was weighed and powdered in a dry and clean glass mortar. To this, $28.56 \mathrm{ml}$ water was added to the powdered acacia slowly with trituration to form a smooth mucilage followed by the addition of $0.28 \mathrm{ml} \mathrm{CP}$ seed oil and triturated to obtain an even mixture. Then, $56.84 \mathrm{ml}$ coconut oil was introduced in small portions with rapid trituration until a clicking sound was produced and the emulsion becomes white or nearly white to form the primary emulsion after which more water in small portions to the primary 
emulsion with trituration to produce the required volume. Next, the mixture was stirred thoroughly so as to form a uniform emulsion. It was then transferred and stored in a cool and dry place [12].

\section{Experimental animals}

Ten weeks old healthy Swiss albino mice were selected in this study $(n=4)$, weighing around 20-25 g was purchased from disease-free small animal house, Kerala Veterinary College, Mannuthy. Animals were housed separately in groups of 4 per cage under laboratory conditions with alternating light and dark cycle of $12 \mathrm{~h}$ each having free access to food and water. The animals were kept fasting $2 \mathrm{~h}$ before and $2 \mathrm{~h}$ after drug administration. The animals were acclimatized for at least 5 days before the actual dosing schedule started between 09:00 and 17:00 h. The laboratory animals for using in this experimental study were approved by the Institutional Animal Ethics Committee of NCP (Registration No. 1411/P0/Re/S/11/The Committee for the Purpose of Control and Supervision of Experiments on Animals).

\section{Acute toxicity study}

Acute oral toxicity study for the extract was conducted in accordance with the Organization for Economic Cooperation and Development (OECD) guidelines No. 423. The female mice were used for the study. Sixteen female mice were divided into four groups, with each containing four animals. Group I received 1\% Tween 20 and dimethyl sulfoxide. Group II, III, and IV received CP seed oil orally, at doses of 300, 2000, and $5000 \mathrm{mg} / \mathrm{kg}$ body weight, respectively. After dosing, each animal was observed carefully, at least once during the first $30 \mathrm{~min}$, periodically during the first $24 \mathrm{~h}$. Special attention was given during the first $3 \mathrm{~h}$ and daily thereafter for a total of 14 days $[13,14]$. Behavioral profile (alertness, restlessness, irritability, and fearfulness), autonomic profile (defecation and urination), neurologic profile (locomotion, reactivity, touch, and pain response), physical states such as changes in skin, fur, eyes, mucous membranes, including respiratory, circulatory, central nervous systems, and somatomotor activity, and any lethality or death were also considered during observation. Animals were also carefully observed for tremors, convulsions, salivation, diarrhea, lethargy, sleep, and coma. The body weight, food, and water intake were monitored weekly.

\section{Subacute toxicity study}

The repeated dosing in oral toxicity study has been conducted as the bedside observation as per the OECD 407 for 28 days. Albino young, healthy male mice and non-pregnant female mice were used in this study. Animals were divided into four groups with four animals in each group ( $\mathrm{n}=16 ; 8$ female and 8 male). Group I received 1\% Tween 20 and dimethyl sulfoxide. Group II, III, and IV received CP seed oil orally at doses of 300,2000, and $5000 \mathrm{mg} / \mathrm{kg}$ body weight, respectively. Clinical signs were observed daily during the 28 days of the treatment period. Body weights were measured once a week. On the $29^{\text {th }}$ day, the animals were kept to overnight and blood samples were collected via retroorbital puncture for biochemical analysis.

\section{Mortality rate and sign of toxicity of $\mathrm{CP}$}

The observations after the 28 days study have been made to record the rate of mortality and any other sign of toxicity than the signs observed in acute and subacute toxicity studies for the groups received CP seed oil orally at doses of 300,2000 , and $5000 \mathrm{mg} / \mathrm{kg}$ body weight, respectively.

\section{Effect of CP on mean body weight changes in mice}

The change in body weight is a very important and conclusive sign of the toxicity caused to the animals by any of the doses. A dose with $10 \%$ or more reduction in the body weights declared to be a toxic dose. The animals treated with CP will be observed for their growth pattern and body weight after oral administration of the $2000 \mathrm{mg} / \mathrm{kg}$ extract.

\section{Statistical analysis}

Data were presented as mean \pm SEM. Two way ANOVA followed by Tukey-Kramer post-tests was applied on GraphPad Prism version 5. $\mathrm{p}<0.001$ was considered statistically significant.

\section{RESULTS}

\section{Preliminary phytochemical screening}

Preliminary phytochemical screening of $\mathrm{CP}$ seed oil was performed and the observations are summarized in Table 1:

\section{Acute toxicity study}

As per the OECD guidelines, to establish the safety and efficacy of a new drug, toxicological studies are crucial in animals like mice, rat, guinea pig, dog, rabbit, and monkey under various conditions of the drug employed. Toxicological studies aid in deciding whether a new drug should be adopted for clinical use or not. OECD guidelines -401 , 423 , and 425 intercepts the use of drugs clinically without its clinical trial and the related toxicity studies. Depending on the duration of drug exposure to animals, toxicological studies are of three types: Acute, subacute, and chronic toxicological studies.

The present study has been undertaken to estimate the toxic effects of $\mathrm{CP}$ in Swiss albino mice (female) for a period of 14 days using OECD 423 (acute toxic class method) as per the method discussed above in acute toxicity study. Their results and observations were recorded accordingly $[13,14]$.

\section{Mortality rate and sign of toxicity of CP}

Mortality rate and sign of toxicity of CP were carried out conforming to OECD guidelines -423 as per the method discussed above. No symptoms of toxicity, morbidity, or mortality were noted in animals during the 14 days period following single oral administration at a selected dose level of CP (2000 mg/kg). The CP oil was safe until $2000 \mathrm{mg} / \mathrm{kg}$ body weight and its lethal dose would be greater than that of the test doses. The results were summarized in Tables 2 and 3:

\section{Effect of CP subacute toxicity study}

The repeated dosing oral toxicity study been conducted for 28 days. The effect of CP on cage-side observations was carried out as per the method discussed in subacute toxicity in the study. After oral administration of vehicle and extract, animals were observed continuously during the first $30 \mathrm{~min}$ after dosing and observed periodically (with special attention given during the first $4 \mathrm{~h}$ ) for the next $24 \mathrm{~h}$ and then daily thereafter, for 28 days. All observations were systematically recorded, with individual records being maintained for each animal. Observations include changes in skin and fur, eyes, mucous membrane, and behavioral pattern. Attention was given for monitoring of tremors, convulsions, salivation, diarrhea, lethargy, sleep, coma, and mortality. Further individual body weights of animals were recorded before the

Table 1: Observations of the preliminary phytochemical screening

\begin{tabular}{ll}
\hline Test & Observation \\
\hline Test for alkaloids & \\
a. Mayer's test & Negative \\
b. Dragendorff's test & Negative \\
c. Wagner's test & Negative \\
Test for carbohydrates & \\
a. Molisch's test & Negative \\
b. Benedict's test & Negative \\
c. Fehling's test & Negative \\
Test for proteins & \\
a. Millon's test & Negative \\
b. Biuret test & Negative \\
Test for saponins glycoside & \\
Foam test & Negative \\
Test for tannins & Negative \\
Test for flavonoids & \\
Shinoda test & Negative \\
Test for steroids & \\
Liebermann-Burchard reaction & Positive \\
Test for terpenoids & Negative \\
Test for glycosides & Negative \\
\hline
\end{tabular}


administration of drug on $1^{\text {st }}$ day of the study and thereafter on the $7^{\text {th }}$ and $14^{\text {th }}$ day of the experiment. Changes in the weight of individual animals were calculated. The results were summarized in Table 4 :

\section{Effect of CP on mean body weight changes in mice}

A dose which produces $10 \%$ or more reduction in the body weights was considered to be a toxic dose. The effect of $\mathrm{CP}$ on body weight changes in mice was observed as per the method discussed above. The animals treated with CP showed a normal growth pattern and body weight after oral administration of $2000 \mathrm{mg} / \mathrm{kg}$ extract.

It indicates that the administration of the extract does not affect the normal growth of the animals. The results were summarized in Fig. 1.

Table 2: Observations of acute toxicity study

\begin{tabular}{|c|c|c|c|c|c|}
\hline \multirow[t]{2}{*}{ S. No. } & \multirow[t]{2}{*}{ Parameters } & \multicolumn{4}{|c|}{ Observations } \\
\hline & & $2 \mathrm{~h}$ & $12 \mathrm{~h}$ & $24 \mathrm{~h}$ & $72 \mathrm{~h}$ \\
\hline \multirow[t]{5}{*}{1} & Behavioral profile & & & & \\
\hline & a. Alertness & Normal & Normal & Normal & Normal \\
\hline & b. Restlessness & Normal & Normal & Normal & Normal \\
\hline & c. Irritability & Normal & Normal & Normal & Normal \\
\hline & d. Fearfulness & Normal & Normal & Normal & Normal \\
\hline \multirow[t]{3}{*}{2} & Autonomic profile & & & & \\
\hline & a. Defecation & Normal & Normal & Normal & Normal \\
\hline & b. Urination & Normal & Normal & Normal & Normal \\
\hline \multirow[t]{5}{*}{3} & Neurologic profile & & & & \\
\hline & a. Locomotion & Normal & Normal & Normal & Normal \\
\hline & b. Reactivity & Normal & Normal & Normal & Normal \\
\hline & c. Touch response & Normal & Normal & Normal & Normal \\
\hline & d. Pain response & Normal & Normal & Normal & Normal \\
\hline \multirow[t]{5}{*}{4} & Physical profile & & & & \\
\hline & a. Texture of fur & Normal & Normal & Normal & Normal \\
\hline & b. Nasal secretions & Normal & Normal & Normal & Normal \\
\hline & c. Ear secretions & Normal & Normal & Normal & Normal \\
\hline & $\begin{array}{l}\text { d. Color and texture } \\
\text { of feces }\end{array}$ & Normal & Normal & Normal & Normal \\
\hline 5 & Lethality & Absent & Absent & Absent & Absent \\
\hline
\end{tabular}

Table 3: Mortality rate and sign of toxicity of Celastrus paniculatus

\begin{tabular}{llll}
\hline Groups & Dose (mg/kg) & $\begin{array}{l}\text { Sign of toxicity } \\
\text { (ST/NB) }\end{array}$ & $\begin{array}{l}\text { Mortality } \\
\text { (D/S) }\end{array}$ \\
\hline Group I & $5 \mathrm{mg} / \mathrm{kg}$ & $0 / 3$ & $0 / 3$ \\
Group II & $50 \mathrm{mg} / \mathrm{kg}$ & $0 / 3$ & $0 / 3$ \\
Group III & $300 \mathrm{mg} / \mathrm{kg}$ & $0 / 3$ & $0 / 3$ \\
Group IV & $2000 \mathrm{mg} / \mathrm{kg}$ & $0 / 3$ & $0 / 3$ \\
\hline
\end{tabular}

The values are expressed as number of animals $(n=4)$, where ST: Sign of toxicity, NB: Normal behavior, D: Animals died, S: Animals survived
No significant changes were observed in body weight when compared with control. The values are expressed as mean $\pm S D, n=4$. The statistical analysis was carried out using multiple t-test followed by Tukey's multiple comparison test.

\section{DISCUSSION}

Plant origin drugs are known to play a vital role in the management of various chronic diseases and alternative sources to allopathic pharmaceutical drugs in recent times. The herbal products ensure safety in contrast to the synthetics that are regarded as unsafe to humans and environment. However, the use of these products should be based on the scientific origin; or else they may be futile and unreliable. Furthermore, the irrational use of this phytotherapy may cause serious toxicity in humans. Unfortunately, a large proportion of the population of humans underestimates the toxicity of natural products and does not realize that these agents could be as toxic or more than synthetic drugs.

Toxicity testing is salient in the screening of newly developed drugs before it is marketed for human use. The guiding principles of toxicity testing are to check the effect of the test substances on laboratory animals and its direct toxic effect on humans and furthermore the exposure of laboratory animals to high doses to evaluate its possible hazard on humans that are exposed to a much lower dose.

Toxicity testing employs an array of test in different species of animals with long-term administration of drug, regular monitoring of physiological, biochemical abnormalities, and detailed post mortem examination toward the end of the trial to detect gross or histological abnormalities.

In acute toxicity studies, a single dose of the drug is given in large quantities on a particular animal species to determine the immediate toxic effect. It is used to determine $\mathrm{LD}_{50}$ of drugs or chemicals and natural products.

As per the OECD guidelines, to establish the safety and efficacy of a new drug, toxicological studies are crucial in animals such as mice, rat, guinea pig, dog, rabbit, and monkey under various conditions of the drug employed. Toxicological studies aid in deciding whether a new drug should be adopted for clinical use or not. OECD 401, 423, and 425 intercepts the use of drug clinically without its clinical trial and the related toxicity studies. Depending on the duration of drug exposure to animals, toxicological studies are of three types: Acute, subacute, and chronic toxicological studies.

The acute toxicity study of CP was carried out as per OECD - 423 guidelines. On the basis of literature reviews, it has been reported that CP seems to be safe at a dose level of $2000 \mathrm{mg} / \mathrm{kg}$, and the $\mathrm{LD}_{50}$ is considered to exceed $2000 \mathrm{mg} / \mathrm{kg}[13,14]$. A single dose of CP seed oil when administered orally and observed for a period of 14 days did not

Table 4: Effect of Celastrus paniculatus subacute toxicity study at bedside

\begin{tabular}{|c|c|c|c|c|c|}
\hline Parameters & Control & $\begin{array}{l}\text { Celastrus paniculatus } \\
\text { at } 5 \mathrm{mg} / \mathrm{kg}\end{array}$ & $\begin{array}{l}\text { Celastrus paniculatus } \\
\text { at } 50 \mathrm{mg} / \mathrm{kg}\end{array}$ & $\begin{array}{l}\text { Celastrus paniculatus at } \\
300 \mathrm{mg} / \mathrm{kg}\end{array}$ & $\begin{array}{l}\text { CP at } \\
2000 \mathrm{mg} / \mathrm{kg}\end{array}$ \\
\hline Skin and fur & Normal & Normal & Normal & Normal & Normal \\
\hline Eye lacrimation & Normal & Normal & Normal & Normal & Normal \\
\hline Salivation & Normal & Normal & Normal & Normal & Normal \\
\hline Diarrhea & Nil & Nil & Nil & Nil & Nil \\
\hline Lethargy & Nil & Nil & Nil & Nil & Nil \\
\hline Respiration & Normal & Normal & Normal & Normal & Normal \\
\hline Convulsions & Nil & Nil & Nil & Nil & Nil \\
\hline Coma & Nil & Nil & Nil & Nil & Nil \\
\hline Locomotor activity & Nil & Nil & Nil & Nil & Nil \\
\hline Excitement & Nil & Nil & Nil & Nil & Nil \\
\hline Other symptoms & Nil & Nil & Nil & Nil & Nil \\
\hline Morbidity & Nil & Nil & Nil & Nil & Nil \\
\hline Mortality & Nil & Nil & Nil & Nil & Nil \\
\hline
\end{tabular}




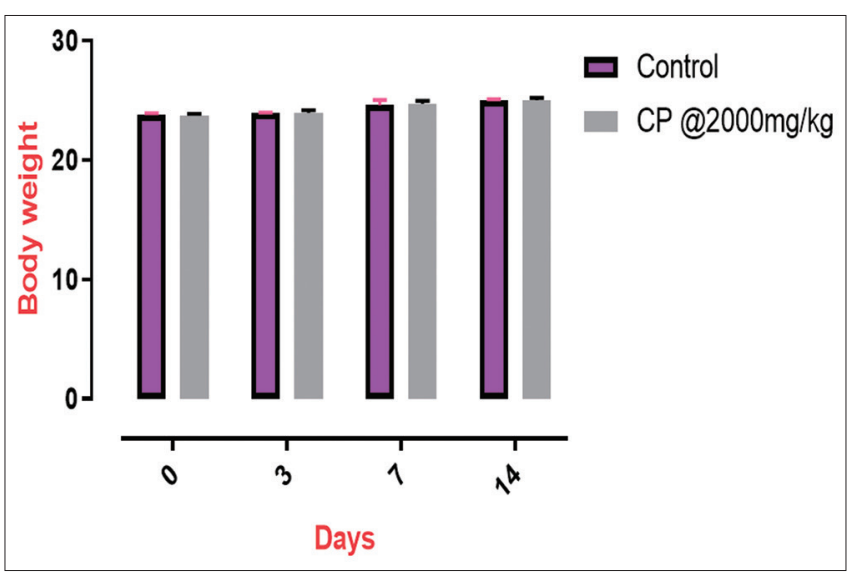

Fig. 1: Effect of Celastrus paniculatus on mean body weight changes in mice

exhibit any mortality or toxic symptoms (Table 2). Acute oral toxicity studies aid in evaluating the intrinsic toxicity of the substances and effect on the living tissues [15].

Cage side observations such as behavior, breathing, skin fur, water consumption, and food intake were found to be normal. All treated animals were in live condition after the administration of CP. Mortality was absent in both treatment and control groups (Table 2). This indicates that there were no disturbances in carbohydrate, protein, or fat metabolism. All the treated mice did not exhibit any significant weight loss throughout the experiment, suggesting that the animals were free from wasting syndrome. They presented normal growth pattern and body weight which is similar to the normal control. Decrease or increase in the body weights was associated with toxic effects of chemicals and drugs accompanied with the accumulation of fats and physiological adaptation responses to the plant extracts rather than to the toxic effects of chemicals or drugs that lead to decrease appetite and, hence, lower caloric intake by the animal. Thus, the treatment with CP did not affect the normal health status of animals. It is suggested that CP is considered safe or practically non-toxic. Any pharmaceutical drug or compound with the oral $\mathrm{LD}_{50}$ higher than $1000 \mathrm{mg} / \mathrm{kg}$ could be considered safe and low toxic. This suggests that CP is practically non-toxic in a single dose level of $2000 \mathrm{mg} / \mathrm{kg}$ body weight $[13,14]$. These results further open the scope for further research on the effects of the plant at the genetic level [16].

\section{CONCLUSION}

The acute toxicity study of CP was carried out as per OECD - 423 guidelines. On the basis of literature reviews, it has been reported that $\mathrm{CP}$ seems to be safe at a dose level of $2000 \mathrm{mg} / \mathrm{kg}$, cage side observations indicated that there were no signs of toxicity or changes in physical appearances such as skin, fur, eyes, mucous membrane, behavioral pattern, salivation, and sleep of the treated as well as the control animals were found to be normal. Tremors, lethargy, diarrhea, coma, and lethality did not occur in any of the animal at the end of 14 and 28 days of the observation period.

\section{AUTHORS' CONTRIBUTIONS}

Conceptualization: Bharat Mishra, Data Collection: Elezabeth John, Krupamol Joy, and Bharat Mishra Formal Analysis: Badmanaban R, Aleesha R, and Bharat Mishra Funding Acquisition: Bharat Mishra and Elezabeth John, Methodology: Badmanaban R, Aleesha R, and Bharat Mishra Project Administration: Bharat Mishra and Elezabeth Visualization: Bharat Mishra and Elezabeth Writing - Original Draft: Bharat Mishra, Elezabeth, and Krupamol Joy Writing - Review and Editing: Bharat Mishra, Elezabeth, and Krupamol Joy.

\section{CONFLICTS OF INTEREST}

The authors declared no conflicts of interest.

\section{AUTHORS' FUNDING}

The project was self-funded.

\section{REFERENCES}

1. Balunas MJ, Kinghorn AD. Drug discovery from medicinal plants. Life Sci 2005;78:431-41.

2. Younus M. Ethno botanical study and traditional uses of Celastrus paniculatus. Int J Innov Sci Eng Technol 2015;2:139-43.

3. Bhanumathy M, Chandrashekhar SB, Somasundaram T. Phytopharmacology of Celastrus paniculatus: An overview. Int J Pharm Sci Drug Res 2010;2:176-81.

4. Godkar PB, Gordon RK, Ravindran A, Doctor BP. Celastrus paniculatus seed water soluble extracts protect against glutamate toxicity in neuronal cultures from rat forebrain. J Ethnopharmacol 2004;93:213-9.

5. Valecha R, Dhingra D. Behavioral and biochemical evidences for antidepressant-like activity of Celastrus paniculatus seed oil in mice. Basic Clin Neurosci 2016;7:49-56.

6. Kaur D, Shri R, Kamboj A. Evaluation of anti-anxiety effect of Brassica oleracea L. extracts in experimental animals. Pharmacogn J 2017;9:638-43.

7. Bhagya V, Christofer T, Shankaranarayana Rao BS. Neuroprotective effect of Celastrus paniculatus on chronic stress-induced cognitive impairment. Indian J Pharmacol 2016;48:687-93.

8. Borrelli F, Borbone N. Potent relaxant effect of a Celastrus paniculatus extract in the rat and human ileum. J Ethnopharmacol 2009;122:434-8.

9. Lekha G, Mohan K, Samy IA. Effect of Celastrus paniculatus seed oil (Jyothismati oil) on acute and chronic immobilization stress induced in swiss albino mice. Pharmacogn Res 2010;2:169-74.

10. Sharwan G, Jain P, Pandey R, Shukla SS. Toxicity profile of traditional herbal medicine. J Ayu Herb Med 2015;1:81-90.

11. Thomson J. Handbook of Radioactivity Analysis. $3^{\text {rd }}$ ed. San Diego, CA: Academic Press; 2012.

12. Mehta RM. Textbook of Pharmaceutics. $1^{\text {st }}$ ed. New Delhi: Vallabh Prakashan Publishers; 1997.

13. Lalitha P, Shuashini KS, Jayanthi P. Acute toxicity study of extracts of Eichhornia crassipes (Mart). Solms. Asian J Pharm Clin Res 2012;5:59-61.

14. Organisation for Economic Co-operation and Development. OECD Guideline for Testing of Chemicals. Acute Oral Toxicity-Acute Toxic Class Method 423 Adopted. Paris: Organisation for Economic Cooperation and Development; 2001. p. 1-14.

15. Estuningtyas A, Widiasari S, Kusmardi K. Acute toxicity of chitosan nanoparticles containing mahkota dewa (Phaleria macrocarpa) leaf extract and anti-inflammatory effects in a dextran sodium sulfate-induced mouse model of ulcerative colitis. Int J Appl Pharm 2018;10:6-10.

16. Shivaraj YN, Govind SR, Jogaiah S, Sannaningaiah D. Functional analysis of medicinal plants using systems biology approaches. Int J Pharm 2015;7:41-3. 